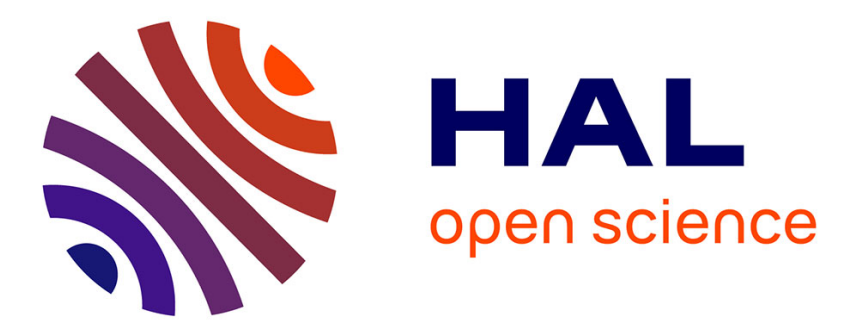

\title{
VR-PMS: a new approach for performance measurement and management of industrial systems
}

\author{
Francois B. Vernadat, Liaqat Shah, Alain Etienne, Ali Siadat
}

\section{To cite this version:}

Francois B. Vernadat, Liaqat Shah, Alain Etienne, Ali Siadat. VR-PMS: a new approach for performance measurement and management of industrial systems. International Journal of Production Research, 2013, 51 (23-24), pp.7420-7438. hal-01081311

\section{HAL Id: hal-01081311 https://hal.science/hal-01081311}

Submitted on 7 Nov 2014

HAL is a multi-disciplinary open access archive for the deposit and dissemination of scientific research documents, whether they are published or not. The documents may come from teaching and research institutions in France or abroad, or from public or private research centers.
L'archive ouverte pluridisciplinaire $\mathbf{H A L}$, est destinée au dépôt et à la diffusion de documents scientifiques de niveau recherche, publiés ou non, émanant des établissements d'enseignement et de recherche français ou étrangers, des laboratoires publics ou privés. 


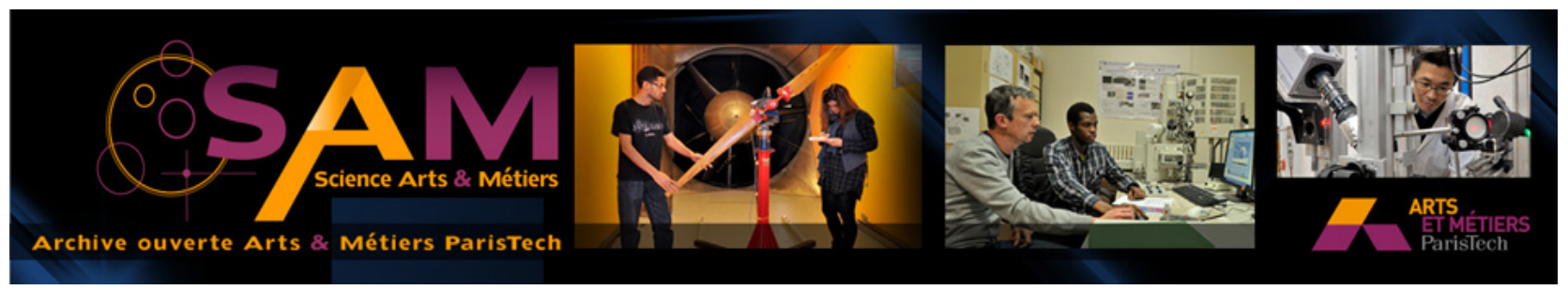

Science Arts \& Métiers (SAM)

is an open access repository that collects the work of Arts et Métiers ParisTech researchers and makes it freely available over the web where possible.

This is an author-deposited version published in: http://sam.ensam.eu

Handle ID: .http://hdl.handle.net/10985/8834

\section{To cite this version :}

François VERNADAT, Liaqat SHAH, Alain ETIENNE, Ali SIADAT - VR-PMS: a new approach for performance measurement and management of industrial systems - International Journal of Production Research - Vol. 51, n²3-24, p.7420-7438 - 2013 


\section{International J ournal of Production Research}

\section{VR-PMS: a new approach for performance measurement and management of industrial systems}

F. Vernadat ${ }^{a}$, L. Shah $^{b}$, A. Etienne ${ }^{b} \&$ A. Siadat ${ }^{b}$

a Information Systems \& Methods Unit/ DIT European Court of Auditors, 12, rue Alcide de Gasperi, L-1615, Luxembourg

${ }^{\mathrm{b}}$ Laboratory LCFC Arts et Métiers ParisTech, Centre de Metz, 4, Rue Augustin Fresnel, F-57070, Metz, France

Version of record first published: 08 Feb 2013. 


\title{
VR-PMS: a new approach for performance measurement and management of industrial
} systems

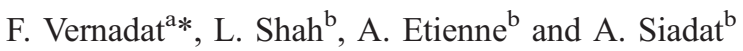 \\ ${ }^{a}$ Information Systems \& Methods Unit/DIT European Court of Auditors, 12, rue Alcide de Gasperi, L-1615, Luxembourg; \\ ${ }^{b}$ Laboratory LCFC Arts et Métiers ParisTech, Centre de Metz, 4, Rue Augustin Fresnel, F-57070, Metz, France
}

(Final version received 28 October 2012)

\begin{abstract}
A new performance measurement and management framework based on value and risk is proposed. The proposed framework is applied to the modelling and evaluation of the a priori performance evaluation of manufacturing processes and to deciding on their alternatives. For this reason, it consistently integrates concepts relevant to objectives, activity, and risk in a single framework comprising a conceptual value/risk model, and it conceptualises the idea of value- and riskbased performance management in a process context. In addition, a methodological framework is developed to provide guidelines for the decision-makers or performance evaluators of the processes. To facilitate the performance measurement and management process, this latter framework is organised in four phases: context establishment, performance modelling, performance assessment, and decision-making. Each phase of the framework is then instrumented with stateof-the-art quantitative analysis tools and methods. For process design and evaluation, the deliverable of the value- and risk-based performance measurement and management system (VR-PMS) is a set of ranked solutions (i.e. alternative business processes) evaluated against the developed value and risk indicators. The proposed VR-PMS is illustrated with a case study from discrete parts manufacturing but is indeed applicable to a wide range of processes or systems.
\end{abstract}

Keywords: performance management; value management; risk management; process modelling; objectives modelling; discrete event simulation and decision-making support

\section{Introduction}

Performance measurement and management (PMM) has been posing daunting challenges to companies in terms of meeting multiple stakeholder objectives for several decades (Globerson 1985). Often, companies are able to meet some objectives but at the expense of others. However, it is not an easy task for companies to meet all of their objectives simultaneously. The issue is complicated further when two or more conflicting objectives are required to be met at the same time, e.g. improving the quality of the product while reducing cost and time objectives. Yet companies are forced to do this owing to fierce competition in an era of globalisation.

Moreover, PMM and the context in which it operates are continuously evolving (Bititci et al. 2011). New business trends bring forward new performance concepts that ultimately shape the PMM systems (Shah 2012). However, major developments in the PMM discipline started in the late 1970s with dissatisfaction with traditional backward-looking accounting systems (Nudurupati et al. 2011). During this period, some authors and practitioners have questioned the veracity of financial-based performance measures and demanded a broader view of performance measures in the face of new trends that took place during this period (Kaplan 1984). As a result, new aspects, mostly non-financial such as flexibility (Slack 1983), time (Stalk 1988), or quality and customer satisfaction (Deming 1982), appeared in the performance measurement arena. These developments turned the PM discipline into a multi-dimensional one (Skinner 1973; Hayes and Abernathy 1980) that led to the introduction of integrated and balanced approaches for PMM (Johnson and Kaplan 1987; Kaplan and Norton 1992). More recently, several new performance measures have been emerging such as agility, reactivity, and even innovation and interoperability.

In response to the multi-dimensional nature of performance, many integrated approaches were developed. The most widely known among such approaches is the Balanced Scorecard (BSC) approach (Kaplan and Norton 1992, 1996, 2004). In addition, other such approaches that gained popularity include ECOGRAI (Bitton 1990; Ducq and Vallespir 2005), SMART (Lynch and Cross 1992), and Performance Prism (Neely, Adam, and Kennerley 2002). Meanwhile, financial-based performance measurement systems such as activity-based costing (Bharara and Lee 1996; 
Brimson 1997), EVA (Stern, Stewart, and Chew 1995) and theory of constraints (TOC) (Goldratt 1990, 1999) continued to evolve and tried to offset the inadequacy of the cost-based systems. More recently, specific frameworks have been developed for the supply chain (Chan and Qi 2003; Gunasekaran, Patel, and McGaughey 2004; Gunasekaran and Kobu 2007; Berrah and Vernadat 2011).

In short, each of the PMM approaches developed so far has both relative strengths and weaknesses. A thorough review and analysis of the existing performance measurement and management system (PMS) approaches and methods reveal that none can globally handle the relevant established performance concepts, i.e. multi-dimensionality, multiple stakeholder perspective, and performance at multiple levels. In addition, risk management is not part of any PMS. Despite the fact that risk is the sole element affecting organisational performance, it is still managed independently of the integrated PMM discipline. The importance of risk to be part of the integrated PMS has been realised too, recently (Cokins 2012). Furthermore, there is little guidance for choosing and implementing performance measures (Shah et al. 2012). In addition, the PMSs most often ignore the consolidation of performance measures to facilitate decision-making. Inter-criteria/measure interaction is generally the ignored aspect in PMM approaches.

Moreover, the existing PMSs are designed for intra-organisational setup and can hardly be applied to the inter-organisational configuration (Shah 2012). The changing nature of business trends, such as collaboration across continents, networking of business entities, green supply chains, sustainability issues and so on, are being changing the very landscape of the PMSs, hence making the existing PMM approaches too restrictive or even inadequate (Bititci et al. 2011).

In view of the current PMM issues, we concentrate our research on the development of a generic approach based on four dimensions: Cost, Benefits, Value, and Risk. Cost is about the price or total cost of the system, product, process, or project being evaluated. Benefits are the potential gains for the organisation. Value is the degree of satisfaction of the stakeholders and especially 'customers'. It is computed as the aggregation of elementary performance indicators relevant for the objective(s) to be satisfied. Risk represents an estimation of the global risk of infringing the achievement of the objective(s). It is also computed as an aggregation of elementary risk values associated with risk factors faced by the system, product, process, or project. Cost and benefits are essential to accept or reject a project or system at first approximation. Value and risk must be optimised once it is accepted and/or can be criteria to abandon the project or system later on at the second approximation if found to be beyond acceptable bounds.

For the sake of conciseness, the paper is restricted to the (value, risk) pair, which is the most innovative, while the cost/benefit aspects have been largely covered in the literature for years. Thus, an original process-centred value and riskbased performance management framework (VR-PMS) is proposed. The idea of process-centred PMS comes from the need to get rid of the archaic conception of organisation, which considers a firm as a black box in which investments flow in, activities happen inside to deliver products or services, and which is controlled on the basis of income statements, balance sheets, and market evaluations. To resolve this issue, a process-centred approach should be devised which considers an organisation as nothing but a bundle of inter-connected activities and decisions (Meyer 2003). These activities incur cost as a result of decisions taken and create value for stakeholders but, at the same time, they are exposed to external as well as internal risks. Furthermore, numerous authors advocate the use of a process centric approach towards PMM (Kueng 2000; Chan and Qi 2003; Meyer 2003; Folan and Browne 2005; Acar, Kadipasaoglu, and Schipperijn 2010). However, a full and consistent process-oriented integrated PMS has still to be proposed.

The VR-PMS approach combines, in a unified framework, fundamental ideas from the value-focused thinking (VFT) method of Keeney (1996) for objectives modelling, the risk-assessment approach of Larson and Kusiak (1996) for modelling and estimating risk, and the information aggregation approach for industrial performance management of Berrah, Mauris, and Vernadat 2006 and Clivillé, Berrah, and Mauris 2007.

\section{Value- and risk-based PMM system (VR-PMS)}

A value- and risk-based approach to PMM using objectives modelling, process modelling, and simulation methodologies should come out into an effective PMS because it can address many of the deficiencies highlighted in Section 1. Value as a performance indicator reflects the satisfaction of multiple stakeholders. It therefore enhances the ability of a decision-maker to act consistently and reduce their cognitive load by normalising multiple, heterogeneous, and conflicting performance measures into a single measure. Similarly, the risk indicator combines various risks of diverse nature into a single normalised measure. To provide an overall solution, value and risk are evaluated in an integrated way employing objectives modelling, modified process modelling, and discrete-event simulation techniques in the framework of VR-PMS.

To this end, VR-PMS is equipped with two frameworks: structural and methodological. The structural framework covers the theoretical aspects of the PMM process by integrating and modelling the relevant performance concepts via a 
conceptual value-risk model. The methodological framework, on the other hand, provides guidelines for value and risk quantification of a process in line with stakeholder expectations.

\subsection{VR-PMS structural framework}

The structural framework of VR-PMS models three views of a process related to objectives, activities, and risks at various abstraction levels. The resulting generic models are then mapped into a combined conceptual value/risk model, which provides the mechanism to facilitate the understanding of the value creation and preservation of a business process.

\subsubsection{Objectives model}

The first step in building a conceptual value model for a process is to identify a set of objectives $O_{i}(i=1, \ldots, n)$, appropriate for the process considered, and to define performance measures $M_{i}(i=1, \ldots, n)$ in order to measure the degree to which these objectives are met. For this purpose, the objectives model inspired by the value-focused thinking framework (VFT) of Keeney (1996) is applied. It provides a structured approach to elicit objectives from stakeholder values usually expressed in the form of qualitative objective statements. The identified fundamental objectives are refined from higher levels to lower levels in a hierarchical structure employing the VFT principles.

The refined objectives on the lower side of the hierarchical structure are quantifiable, and hence, performance measures can be defined for each of them. The defined performance measures form the basis for assessment of alternative processes when VR-PMS is used as a decision-support system. Otherwise, they provide useful information about the process performance. The lower-level objectives, and hence the normalised performance measures (i.e. elementary performance expressions), are then aggregated by means of aggregation operators, ultimately leading to the global process performance.

\subsubsection{Activity model}

Objectives are realised by means of activities that ultimately create value for the stakeholders and, therefore, are central to a process-oriented PMS. For this purpose, they are required to be modelled. The IDEF0 method is commonly used to model activities. It describes an activity in terms of inputs, controls, outputs, and mechanisms (Figure 1). To transform an input into an output, an organisation consumes various resources called mechanisms. However, to ensure the effectiveness and efficiency of this transformation, it is subject to controls for monitoring and control.

From the IDEF0 formulation of an activity, a generic activity model (Figure 2) can be developed for a value model. To this end, additional generic attributes of an activity in the context of performance assessment, namely, cost, time, and quality, are defined. To make the activity model for value creation operational, an activity carrying a certain degree of quality (for instance, maturity, recoverability, performance) consumes cost and time and produces deliverable(s). This deliverable is the interim value in the value perspective whose magnitude is measured with reference to the associated objectives. Additionally, the effectiveness and efficiency of the activity to produce the interim value are subject to cost, resource, and scheduling models as well as to operating policies, which govern the transformation process of the activity model.

However, the activity is subject to uncertainties in the form of risk factors that may affect its value creation capability. Therefore, a risk model is included to account for the risks.

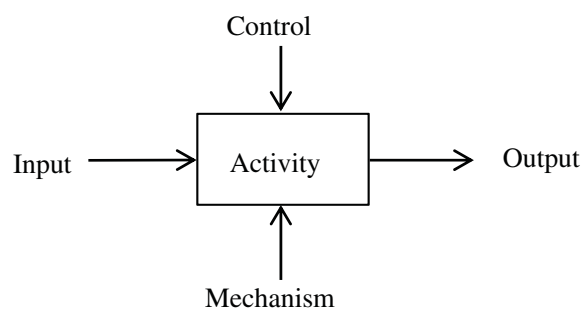

Figure 1. IDEF0 activity diagram. 


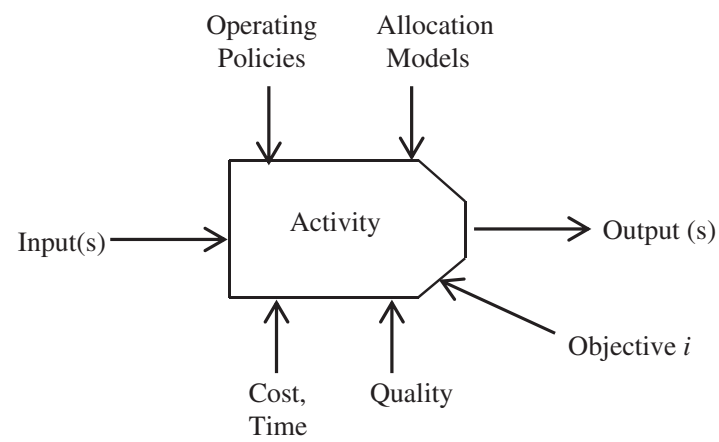

Figure 2. Activity model in a performance perspective.

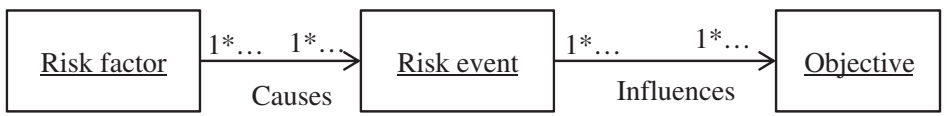

Figure 3. Risk factor and objective relationships.

\subsubsection{Risk model}

Uncertainties reside 'internally' and 'externally' to the activity in the form of risk factors (Salah 2005), which probably trigger the occurrence of risk events whose occurrence can affect the activity progress towards the objective attainment (Figure 3).

To identify risk events and the corresponding risk factors, an objective-driven approach is used. The identified risks are then assessed qualitatively with the help of the activity model using failure mode and effect analysis (FMEA) method and prioritised for further quantitative assessment in the process simulation environment.

To this end, Larson and Kusiak's risk-assessment approach (1996) is relevant, since it is activity-based and can be carried out in the same context, i.e. used for process value assessment. This approach parameterises risk using Kaplan and Garrick's (1981) definition of risk, as expressed by Equation (1):

$$
\hat{R}=(S, P, C)
$$

where $\hat{R}, S, P$ and $C$ represent the estimated risk, risk scenario, likelihood, and consequence, respectively.

The underlying assumption for an activity-based risk assessment is that each activity in a process is exposed to risk factors $R F_{i},(i=1, \ldots, n)$ and thus can trigger one to many risk events, which in turn can affect the attainment of process objectives (as illustrated in Figure 4).

To calculate the global risk for an individual activity, all risks of diverse nature are identified and modelled separately as expressed by Equation (2).

Rish of activity $i=p_{i j}\left(C_{i j}{ }^{q}+C_{i j}{ }^{c}+C_{i j}{ }^{t}+, \ldots\right)$

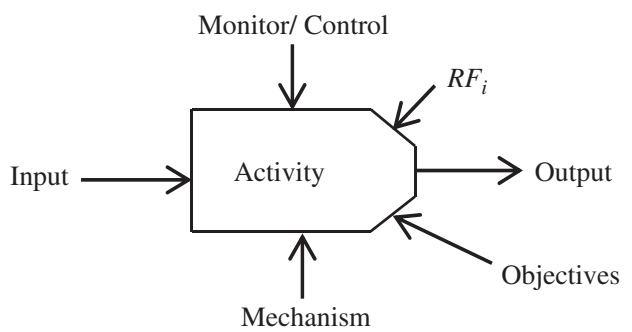

Figure 4. Activity exposure to risk factors. 
where,

$$
\begin{aligned}
& P_{i j} \quad \text { Probability of a risk event } j \text { on activity } i \\
& C_{i j}{ }^{q}, C_{i j}{ }^{c}, C_{i j}{ }^{t} \quad \text { Impact on quality, cost, and time objectives, respectively }
\end{aligned}
$$

Therefore, the global risk for an individual activity $i$ subject to $j$ risk events $j$ is given by Equation (3):

$$
\mathrm{R}_{\mathrm{i}}=\sum_{j=1}^{j} d_{i j}\left(P_{i j} \times C_{i j}\right)
$$

where,

$d_{i j} \quad$ The importance of risk $j$ on activity $i$

$C_{i j} \quad$ The impact of risk $j$ on activity $i$

The global risk $\mathrm{R}\left(\mathrm{p}_{\mathrm{k}}\right)$ of the process path $P_{\mathrm{k}}$ in a process $\mathrm{P}$ is calculated by aggregating global risks of activities in path $P_{\mathrm{k}}$ using Equation (4).

$$
\mathrm{R}\left(\mathrm{p}_{\mathrm{k}}\right)=\sum_{\forall i \in \mathrm{p}_{\mathrm{k}}} \mathrm{R}_{\mathrm{i}}=\sum_{\forall i \in \mathrm{p}_{\mathrm{k}}} \sum_{j=1}^{J} d_{i j}\left(P_{i j} \times C_{i j}\right)
$$

And the probabilities $P_{r}\left(P_{k}\right)$ of the path set (or scenario) must verify Equation (5):

$$
\sum_{\mathrm{k}=1}^{\mathrm{K}} P_{r}\left(P_{k}\right)=1
$$

So, the expected risk of the process $P$ made of $\mathrm{K}$ path sets is given by Equation (6):

$$
\left.E\left(R_{p}\right)=\sum_{K=1}^{K} P_{r}\left(p_{k}\right) \sum_{\forall i \in \mathrm{p}_{k}} \sum_{j=1}^{j} d_{i j}\left(P_{i j} \times C_{i j}\right)\right)
$$

Equation (6) calculates the expected risk of the whole process, $\mathrm{P}$.

\subsubsection{Combined conceptual value/risk model}

Having defined the generic candidate models, they are mapped to form a combined conceptual value-risk model. For this purpose, an ontological analysis has been carried out to define desirable properties for a complete and clear conceptual value-risk model (Shah 2012). In addition, the activity model has been chosen as the primary model to integrate all the desirable properties of the conceptual value/risk model because the activity is the common element to all three can-

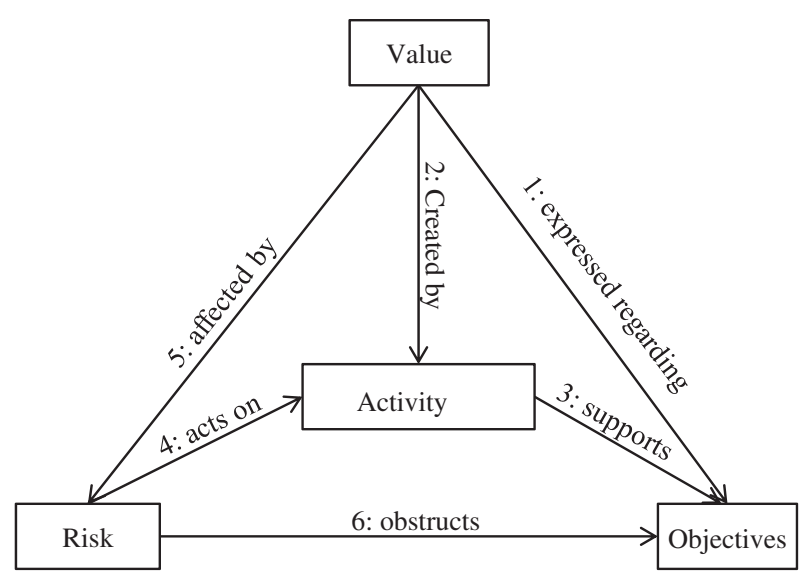

Figure 5. Tetrahedral relationships of value, risk, activity, and objectives. 


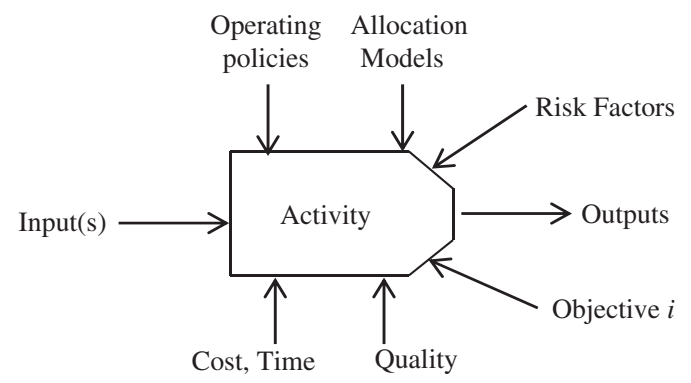

Figure 6. Conceptual value-risk model.

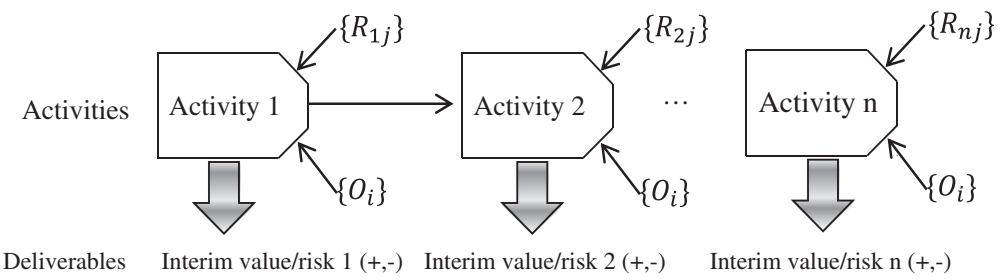

Figure 7. Value-creation process in the presence of risks.

didate models. Thereafter, a tetrahedral structure is proposed to depict the candidate model relationships with the value model as shown in Figure 5.

Figure 5 clearly shows that the (Value, Risk) pair depends on the objective(s) to be achieved. If the objective is changed, the activity will be different, and the expression of the associated value and potential risks will be different.

Based on the relationships established in Figure 5, a conceptual value-risk model is proposed as an adaptation of the IDEF0 activity diagram as depicted in Figure 6. The figure represents an atomic unit of the conceptual value-risk model detailing the fundamental elements and concepts required to value and risk modelling in the process context. To represent objectives and risks on the activity model, the upper right and lower sides of the activity construct are clipped to model risks and objectives, respectively.

The outputs construct in Figure 6 is the interim value $\mu_{i}$ and the interim risk $r_{i}$ created by the activity. The interim value in the context of manufacturing can be a change in the morphology of an unfinished or finished work-piece or information creation from inspection. Similarly, the interim risk $r_{i}$ could be the non-conformity of the created feature to the specification or non-functional objective dissatisfaction such as cost overrun or schedule risk for the activity.

To judge whether the interim value/risk is created or dissipated, it can be obtained by comparing them with the assigned objectives (functional and non-functional ones). The magnitude of the interim value/risk can then be evaluated through value judgements solicited from the business user or process assessor in a systematic manner thanks to several questions as explained in the literature (Bana e Costa, de Corte, and Vansnick 2003). In a decision context, these questions help to determine the preferences and strengths of preferences of the assessor regarding the interim value/risk of several alternatives, which are then transformed into elementary performance expressions (e.g. value and risk functions) employing the theory of preferences (or utility theory).

To obtain the overall value and risk of a process (Figure 7), the interim values and risks obtained in the form of value and risk functions are then aggregated as shown in Equations (7) and (8).

$$
\text { Global Value }=F\left(\mu_{1}, \mu_{2}, \ldots, \mu_{n}\right)
$$

and

$$
\text { Global Risk }=R\left(r_{1}, r_{2}, \ldots, r_{n}\right)
$$

where both $F$ and $R$ represent the Choquet Integral aggregation functions in the framework of VR-PMS.

\subsection{VR-PMS methodological framework}

The methodological framework of VR-PMS consists of four phases to deal with the performance management of a process (it could also be a system or a project): 


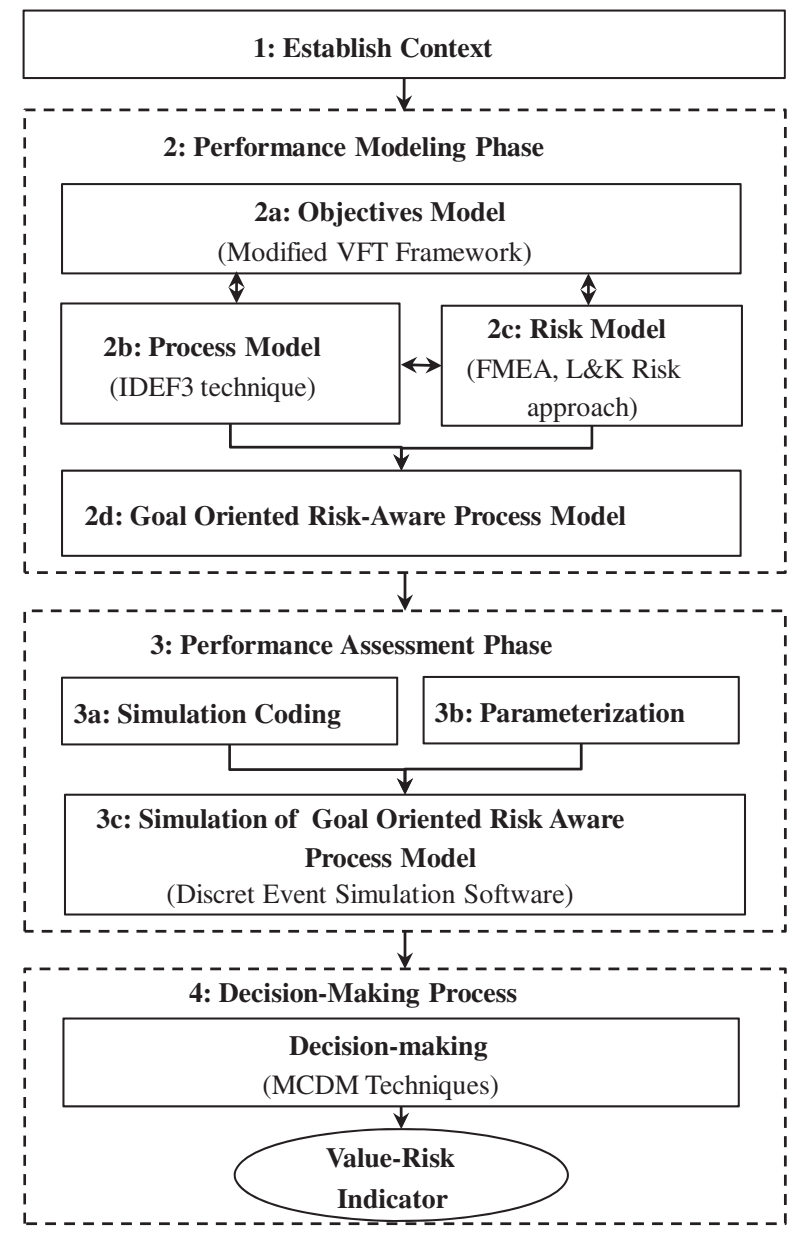

Figure 8. Methodological framework of VR-PMS.

(1) context establishment;

(2) performance modelling;

(3) performance assessment;

(4) decision-making via multi-criteria aggregation.

Figure 8 shows the four phases of the methodological framework and the corresponding tools and techniques used in each phase of the framework.

Each phase of the methodological framework is explained and illustrated with an example in subsequent sections. For this purpose, a case study is used and first presented in the next section.

\subsection{Case-study presentation}

The methodology is illustrated on a case study about a manufacturing company that designs and fabricates product on make-to-order (MTO) basis.

\subsubsection{Reference product}

In this case study, the company produces mechanical locators as a reference product. This is a work-holding device that is placed in a modular fixture to locate a work-piece during machining process. Figure 9 shows the mechanical locator in the loaded and unloaded configuration. 


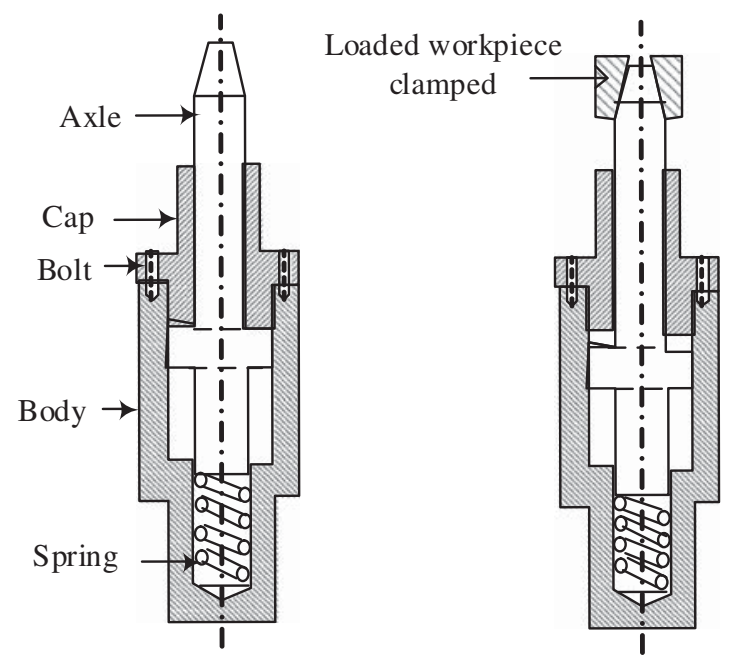

Figure 9. Mechanical locator configurations: free (left) and loaded (right).

To validate the VR-PMS method for value and risk assessment of manufacturing processes under a different set of demands, different manufacturing scenarios have been developed and illustrated (Shah 2012). However, this paper presents only one manufacturing scenario in the case of process design and selection of the best alternative.

\subsubsection{Manufacturing scenario}

The company understudy receives an order of $N$ mechanical locators with a lead time of $T$ weeks. Owing to the short lead time, the client compromises to some extent on the technical performance of the product and, therefore, orders low-quality (LQ) mechanical locators. The high (HQ) and low quality (LQ) of a product can be measured by the satisfaction index (q) detailed in (Anselmetti 2008). In addition, the price $P$ is fixed for each mechanical locator for the defined quality level.

To manufacture and deliver the product, the company purchases springs and bolts from the market while the three other parts, namely axle, body, and cap, are machined at the facility. All the purchased parts are assumed to be available whenever needed.

In the case of non-delivery within the agreed lead time, the company can ask for due-date tolerance, already defined in the contract. If the due date passes, then the company is subject to a penalty cost of $\$ 2$ per unit time tardy up to 5 days. Failing to provide the product in that period of time will lead to cancellation of the product with a backlog cost of $\$ 10$ for $N$ mechanical parts.

\subsection{Application of the methodological framework to the manufacturing scenario}

Having defined the scenario, the methodological framework of VR-PMS is applied to assess the performance of the manufacturing scenario in terms of value and risk on the basis of the conceptual value-risk model. The four phases of the framework are detailed in the following sections.

\subsubsection{Context establishment (phase 1)}

The first phase of the method deals with the identification of the application domain, which can be manufacturing, supply-chain processes, logistic processes, or any administrative processes. The application domain for the current case study is the manufacturing field. Concerning the manufacturing objectives as well as the risk appetite, tolerance, and criteria, they are usually mentioned in the contract with the customer. Moreover, the roles and responsibilities are assigned to deal with the scenario.

The aim of the phase is to identify the stakeholders and their value/concern objects. Indeed, the value creation objects in a given scenario are different to different stakeholders; for instance, performance may be relevant to process owner and customer while compliance quality may be to manager and customer and safety and security as well as operating conditions may be to operators. For this reason, the expectations and the values thereof of the stakeholders vary in 
the scenario. For the purpose of simplicity, the safety and security aspects of the multiple stakeholder perspective are omitted, and the case study focuses on only three main stakeholders: the company, the employee, and the customer, and their respective values and concerns.

\subsubsection{Performance modelling phase (phase 2)}

This phase is concerned with integrating objectives and risks in the framework of the process model. It determines value-driven performance measures using the objectives model, facilitates activity definition to realise the objectives, models the identified activities, identifies risks via an objective-driven approach, and assesses qualitatively the identified risks in the process context with regard to risk-management scope.

2.4.2.1 Objectives modelling (step 2a). Value-driven objectives are qualitative statements reflecting stakeholder expectations. Based on the principles defined in the objectives model of the conceptual value-risk model, the overall fundamental objective is broken down into lower-level objectives and structured into a strict hierarchy.

For the case study at hand, the overall fundamental objective is fixed to be 'order satisfaction'. Asking the question: what do you mean by that for each fundamental objective, brings forward lower-level objectives. For the order-satisfaction objective, they can be low price, high quality, and on-time delivery for the customer (labelled C in Figure 10), low cost and customer satisfaction for the manufacturer (labelled M in Figure 10), and satisfactory working conditions for the operators (labelled $\mathrm{O}$ in Figure 10). The same question is repeated for each of the fundamental objectives until no more refined and quantifiable objectives are determined, which are then structured into a hierarchy as shown in Figure 10.

Many objectives in Figure 10 are self-explanatory. However, some explanations are appropriate. The employee job satisfaction, in the current scenario, refers to the satisfactory working conditions in terms of workload and affiliation of the employees, particularly the operators on the shop floor of the company. Moreover, the compliance objective can be drilled down into individual features $f_{i}$ compliant with the specifications. Furthermore, responsiveness as a dimension of high quality specifies flexibility and availability of the process. Because the current scenario considers one product and one customer, this aspect of high quality, therefore, becomes less relevant.

From the lowest tier of the objectives hierarchy, performance measures are elicited (Figure 11). The importance of the performance measures in the framework of VR-PMS is to use them as tools for the evaluation and assessment of alternative processes.

Since Figure 11 links the process values (i.e. stakeholder expectations) with the performance measures (PMs) via fundamental objectives, it does not describe the mechanism on how these PMs contribute to the process value. To make the process value creation operational, they are linked to activities as the latter are required for realising the objectives.

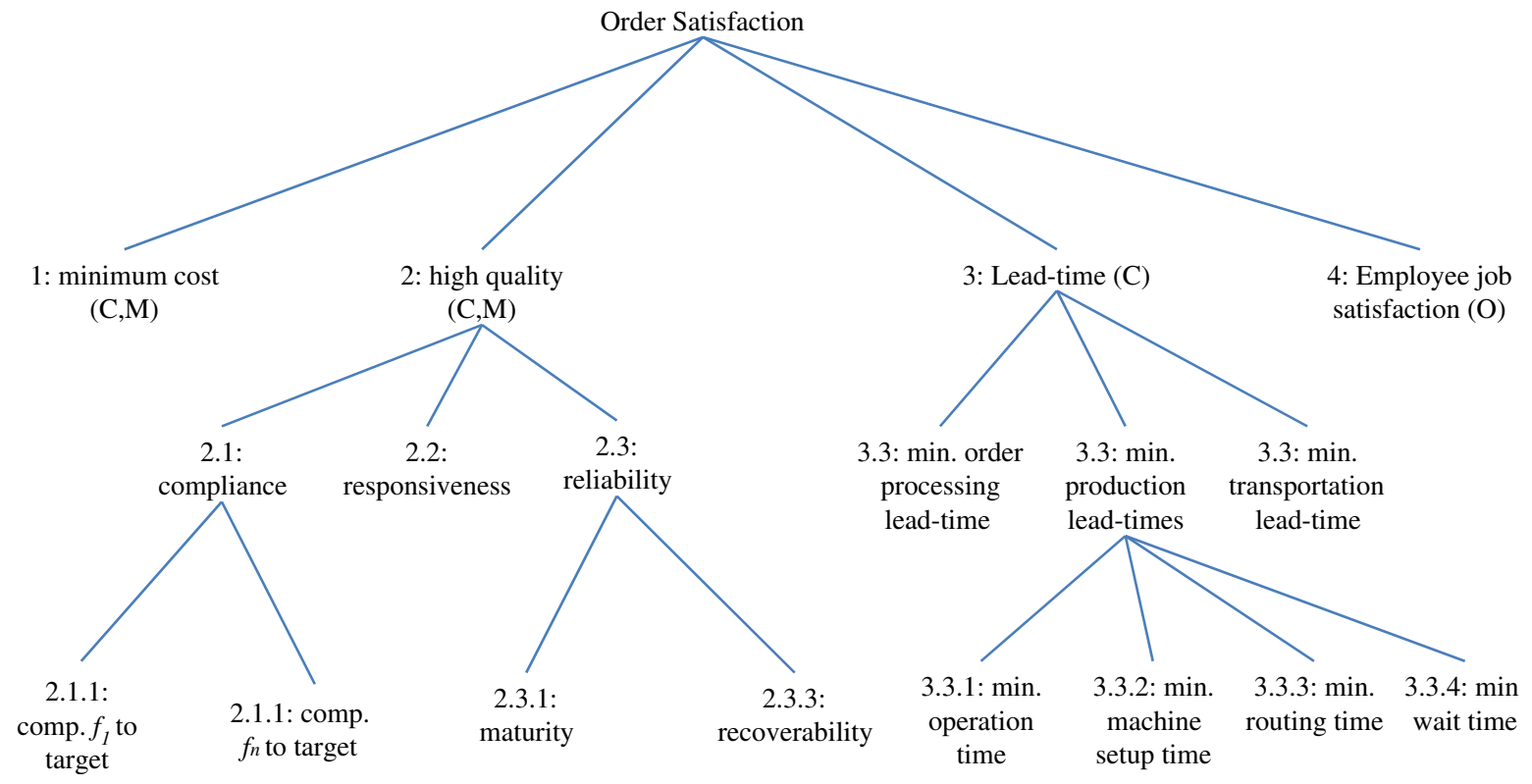

Figure 10. Fundamental objectives hierarchy. 


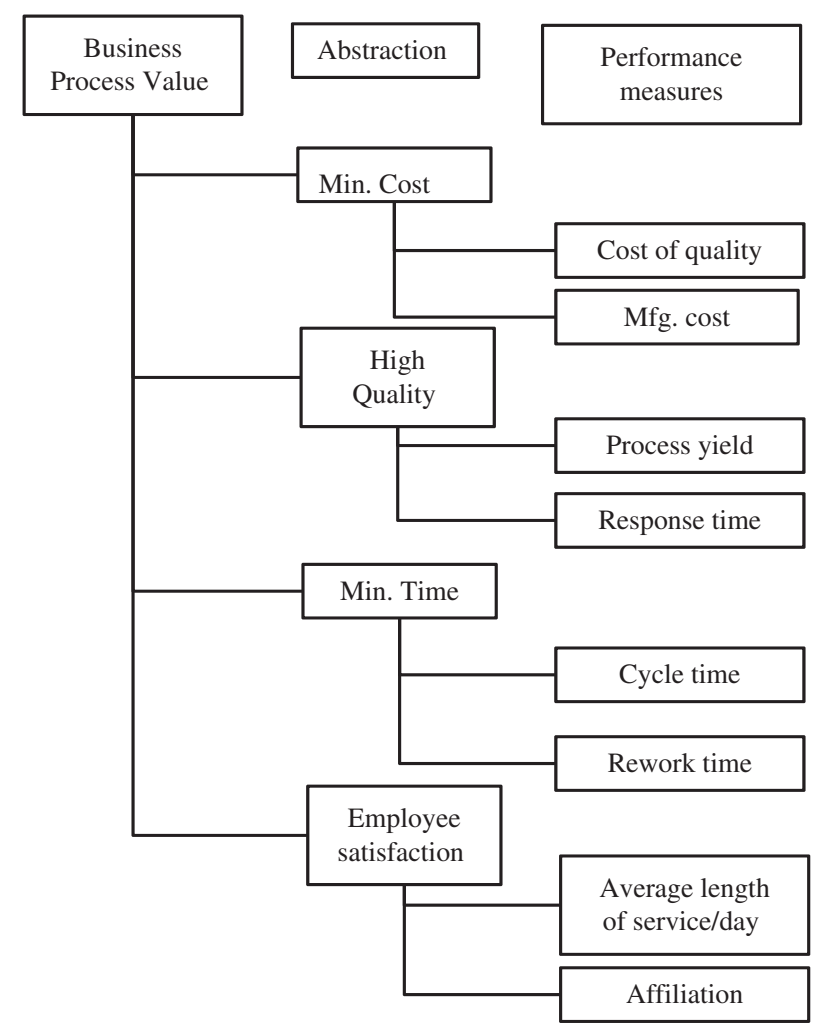

Figure 11. Performance-measures tree (value tree).

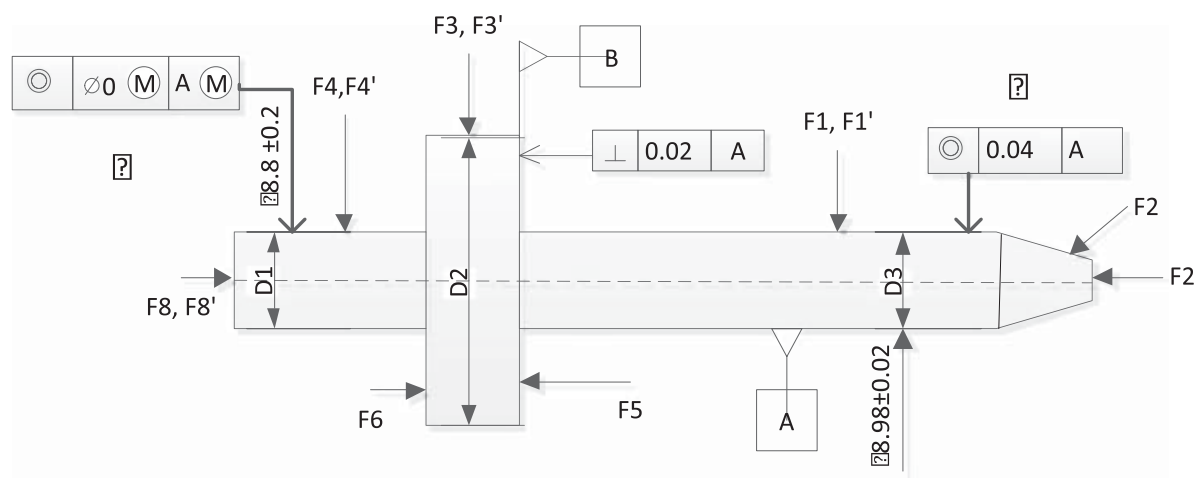

Figure 12. Axle part geometry and tolerances.

2.4.2.2 Activity modelling (step 2b). Process modelling in the current context is the identification and representation of activities to support the realisation of objectives. For this purpose, the current case study relies on the methodology proposed by Sormaz and Khoshnevis (2003) to identify activities and alterative process plans for the mechanical locator. The methodology decomposes the product into geometrical features (e.g. F1 to F8 for axle part as shown in Figure 12). Feature $F_{i}^{\prime}$ in Figure 12 represents the unfinished feature that requires further manufacturing operation in order to be complete. Process candidates are then selected for each decomposed feature using inquiries to the appropriate knowledge base of the manufacturing processes.

Having determined the alternative process plans, they are then evaluated against the performance measures derived from the objectives model (cf. Figure 11), but before that, they are transformed into conceptual process plan models, which serve two purposes: information collection (functional data such as activities) prior to simulation on one hand and providing context for risk assessment on the other hand. Figure 13 depicts a conceptual process plan model. 


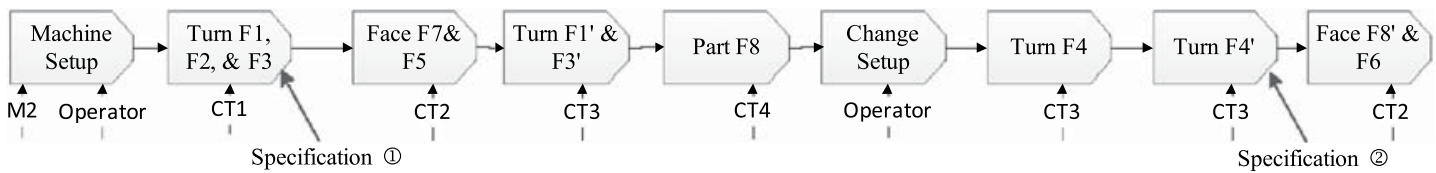

Figure 13. Manufacturing process plan for the axle part.

To model objectives into the process plan model, it is sufficient to associate the functional objectives with each activity in the process plan model. For instance, in Figure 12, two functional objectives in the form of concentricity requirements (specifications (1) and (2)) and for the features F1 and F4 of the axle part have been identified. Thus, these objectives are assigned to the corresponding responsible activities such as 'Turn F1' and 'Turn F4' of the manufacturing process plan model (cf. Figure 13). Concerning the non-functional objectives such as time and cost, they are usually determined in a global way for the whole process via estimation or a simulation experiment.

2.4.2.3 Risk modelling (step 3b). In the process perspective, risk stems from the uncertainty regarding the ability of the process to deliver 'the value proposition', and the consequences thereof. To account for the risk in the manufacturing processes, VR-PMS proposes a two-pronged strategy: objective-driven risk identification and activity-based approach to risk assessment.

(i) Objective-driven approach to risk identification

The general approach to risk identification starts with objectives identification (Moeller 2007; Narasimhan and Talluri 2009). The main idea behind this approach is that risk factors are obstacles to objectives attainment; in other words, objectives capture desirable conditions, whereas risk factors (i.e. obstacles) capture the undesirable conditions (Van Lamsweerde and Letier 2000). An assertion that obstructs the objective attainment is sufficient to identify the relevant risk events.

To determine risks employing the objective-driven approach for the running example, a risk hierarchy similar to the fundamental objectives hierarchy is developed. The approach starts by first defining a global risk such as 'failure to satisfy the order' for a given manufacturing process. The lower-level risks are the inverse mirrors of the fundamental objectives hierarchy, for instance schedule risk corresponds to on-time delivery objective, cost overrun to cost objective, and performance risk corresponds to high quality.

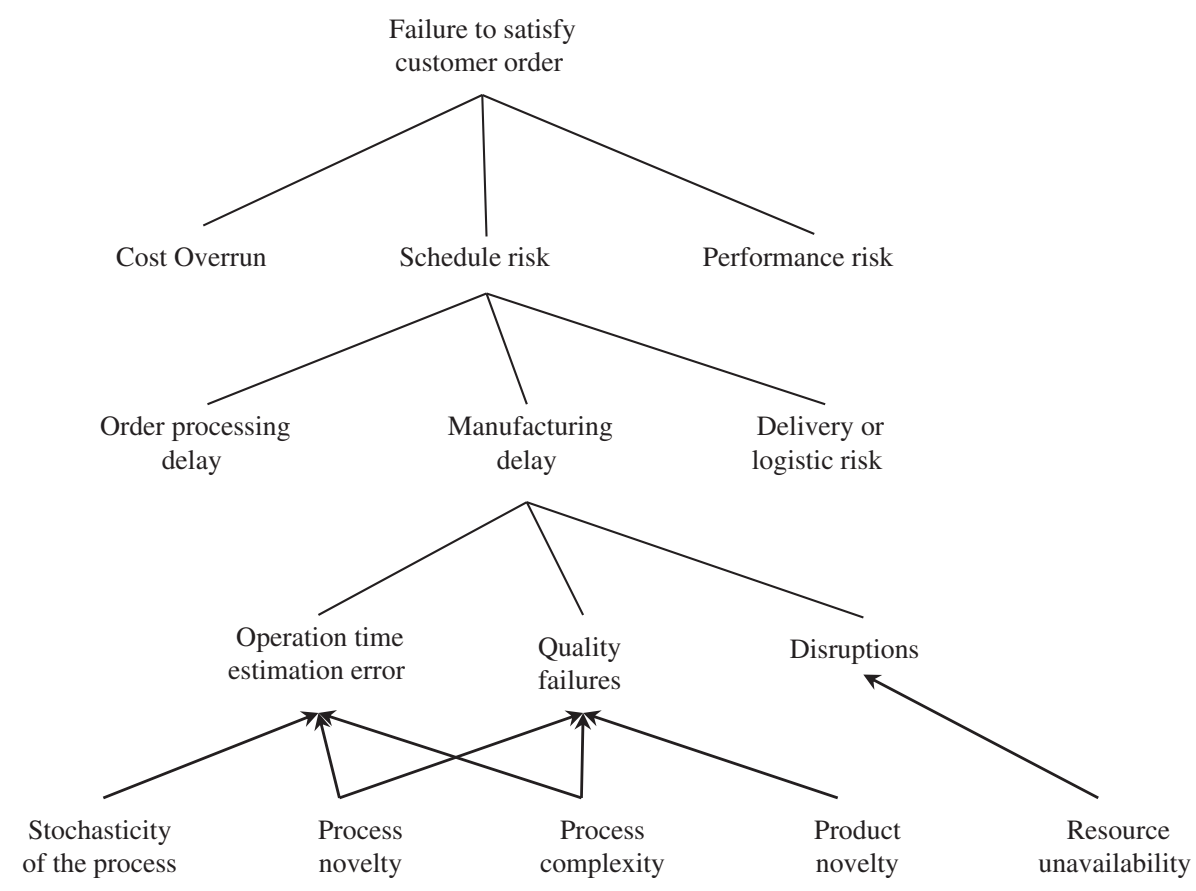

Figure 14. Schedule risk hierarchy. 
Since the 'on-time delivery' is the critical objective in the current scenario, it requires further analysis. For this reason, the schedule risk is refined further using the principles of the modified risk model of VR-PMS. The question 'What do you mean by that' determines lower-level schedule risks such as order-processing delay, manufacturing delay, and delivery delay, as shown in Figure 14.

Since the focus is more on the manufacturing processes, the order processing and logistic delays are excluded from further investigation. The manufacturing delay is further refined to operation time-estimation error, quality failures, and disruptions in the process execution (cf. Figure 14).

The risk model depends on the likelihood and impact of the identified risk events. It is therefore important to determine these two parameters. To calculate the impact of a risk event on a schedule and other fundamental objectives, the contract agreement is consulted. As for the delay, the impact function for the current study $y=f(x)$ is calculated as: $y=$ $a$. $e^{b x}$, where ' $a$ ' and ' $b$ ' are the coefficients and $x$ is the dependent variable indicating the range that exceeds the due date. Similarly, the cost-impact function is calculated assuming a quadratic function (i.e. per unit cost overrun $x$ has an impact $x^{2}$ ). For the quality failure impact, the FMEA technique severity scale is used.

The probability of a risk event can be determined only by putting the risk into the context which is provided by the activity model.

(ii) Activity-based approach to risk assessment

The identified risks cannot be assessed until the contextual information is not available. Because the process model contains sufficient information regarding the execution of the activities, and the environment thereof, they are therefore consulted when analysing a particular risk. For instance, without knowing the type of machine/tool as well as the operator to be employed to machine a critical feature of a part, it is difficult to know whether the risk event may be triggered or not, and hence risk assessment cannot be performed. Before proceeding to a risk analysis, the identified risks are first related to the activities by developing an activity/risk matrix as shown in Table 1.

For instance, the risk event 'Failure to adjust in the modular fixture' can originate if the operation 'Turn F4-B' of the Body process plan is not carried out per specification requirement. Similarly, all the activities of the process plan are linked to the identified risks. Since the activity execution environment (i.e. operating conditions, operator, or machine and tool) is known through the process plan model, it is therefore reasonable to estimate the likelihood and detection parameters for risk analysis in the FMEA table. For instance, if a critical objective is assigned to an error-prone activity, the risk event is then more likely to occur, as compared with an error-free and robust activity. The risks are then assessed qualitatively in the process FMEA table as shown in Table 2.

The critical risks in terms of RPN in the FMEA table are then incorporated in the process model for quantitative assessment.

Table 1. Excerpt of the Activity/Risk Matrix.

\begin{tabular}{lccc}
\hline Risks & Failure to adjust in the modular fixture & Axel/body assembly failure & Duration estimation error \\
\hline Activities & $\times$ & $\times$ & $\times$ \\
Turn F4_B & & $\times$ \\
Turn (F6, F6')_C & & \\
Part F8_A & & \\
\hline
\end{tabular}

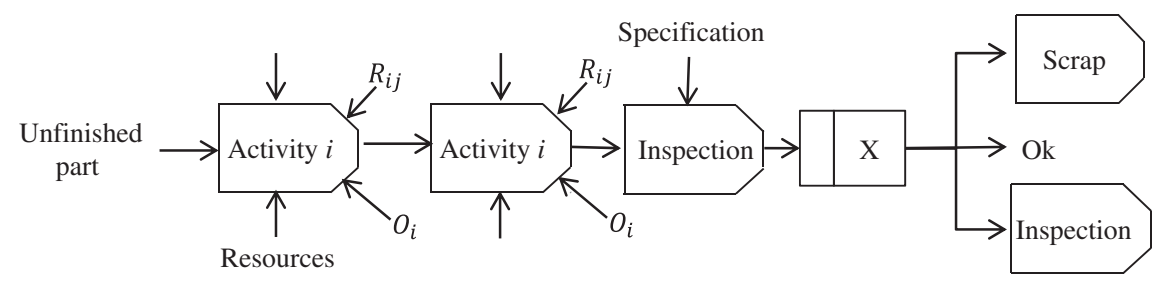

Figure 15. Objective-oriented risk-aware process model. 


\subsubsection{Risk integration in the process model}

The integration of risk in the process model to build a risk-aware business process model is aimed at assessing the critical risks of the FMEA table quantitatively in the simulation environment. All the risks identified and analysed in the FMEA exercise can be included in the process model for further investigation. However, it is practically insignificant. Only high-profile risks should be selected and assessed in the process model. Figure 15 depicts a risk-aware process model.

\subsection{Performance assessment phase (phase 3)}

To quantitatively assess the performance of the process, the current approach employs discrete-event simulation techniques. In the process-centred PMS, discrete-event simulation seems to be an appropriate method, since it offers a great potential in analysing processes (Bosilj-Vuksic et al. 2007). Its major application is to predict and analyse process performances without the process being actually implemented. For this reason, it has proven to be a well-established decision-making tool in engineering offices and among process practitioners.

Furthermore, a process model is a prerequisite to conduct simulation experiments. However, the process model alone is inadequate to provide a complete model for simulation experimentation. Simulation variables (parameters/factors and instructions) in addition to the process model are needed, which makes the process model executable. To this end, the current methodology divides the assessment phase into the following sections.

\subsubsection{Input-data collection}

The input-data generation step is concerned with the requirements gathering phase of the process simulation model under study and is divided into two broad categories:

(1) functional data generation, which represents the activities of the process;

(2) input variables or factors.

Functional data generation refers to the conceptual modelling stage of Robinson's (2004) framework. It involves the real-world abstraction of processes as well as their inputs, outputs, and associated objectives. To this end, the current methodology relies on a performance modelling phase whose deliverable, the objective-oriented risk aware process model, provides such data.

Regarding the input variables, VR-PMS employs many devices to collect them. Shah et al. (2012) suggest dividing the input variables into categories based on their nature and application area in the simulation experiments. Tables 3-5 identify the input parameters for a discrete-event simulation model.

Table 2. Excerpt of the FMEA table for schedule risk.

\begin{tabular}{|c|c|c|c|c|c|c|c|}
\hline Process & Failure mode & Causes (Risk factors) & Effects & $\mathrm{P}$ & $\mathrm{C}$ & $\mathrm{D}$ & RPN \\
\hline Activity i & Duration estimation error & $\begin{array}{l}\text { Unavailable information } \\
\text { Wrong information } \\
\text { Incomplete information } \\
\text { Wrong belief }\end{array}$ & Uncertain Lead time & 5 & 7 & 6 & 210 \\
\hline
\end{tabular}

Table 3. Run parameters for simulation model.

\begin{tabular}{lll}
\hline Parameter types & Categories & Value \\
\hline Part arrival law & NA & EXPO() \\
Parts/arrival & Batches & Number of units/arrivals \\
Replications & NA & 10 \\
Replication length & & 1000 products \\
Warm-up period & NA & XXX time units \\
Process trigger & & Customer order \\
\hline
\end{tabular}


To facilitate the input variables for the process plan, the latter is divided into different categories such as value-adding activities (operations), non-value-adding activities (such as machine and tool setups), quality-control-related activities (e.g. inspection), and resource-specific activities (i.e. capability of machines, machine speed factor) as shown in Table 4.

Moreover, the scenario-specific data (Table 5) can be obtained from the contract agreement between the supplier and the customer. This sort of data represents the process goals, objectives, and constraints.

Evaluation methods: Having defined the parameters for the simulation model, the next step is to select the performance measures against which the simulation models are evaluated. These measures have already been derived using the objectives model of the conceptual value-risk model. However, the calculation method needs to be developed. For the sake of simplicity, the current case study considers only four performance measures as defined in Table 6 .

Similarly, the evaluation methods for risk measures are determined (Table 7).

Table 4. Process plan parameters for simulation model.

\begin{tabular}{|c|c|c|}
\hline Parameter types & Categories & Value \\
\hline Operations & Operation times & TRIA() \\
\hline \multirow[t]{3}{*}{ Inspection } & Inspection type & Manual \\
\hline & Inspection time & NORM() \\
\hline & No. of inspections & 1 to many \\
\hline \multirow[t]{2}{*}{ Setup } & Setup time & NORM() \\
\hline & No. of setups & 1 to many \\
\hline \multirow[t]{2}{*}{ Machine Specific } & Capability of machines & $C P=1$ to 1.67 \\
\hline & Machine speed factor (msf) & $0<\mathrm{msf} \leq 1$ \\
\hline
\end{tabular}

Table 5. Scenario parameters for simulation model.

\begin{tabular}{lll}
\hline Parameter types & Categories & Value \\
\hline Order quantity & NA & D units \\
Objectives/constraints & Product cost & P \$ \\
& Quality level & Satisfaction index \\
& Lead-time & T minutes \\
\hline
\end{tabular}

Table 6. Performance-measures evaluation methods.

\begin{tabular}{|c|c|}
\hline Performance measures & Evaluation methods \\
\hline Manufacturing cycle time $\left(C_{1}\right)$ & $T_{m}=\sum_{i=1}^{N} t^{i}$ activity \\
\hline Manufacturing total cost $\left(C_{2}\right)$ & $C_{m}=\sum_{i=1}^{N} C^{i}$ activity \\
\hline Process yield $\left(C_{3}\right)$ & $(1-\text { scrap parts / total parts })^{\text {pr. step } 1 \times}(1-\text { scrap parts / total parts })^{\text {pr. step } 2}$ \\
\hline Employee/operator satisfaction $\left(C_{4}\right)$ & Length of time an employee work (in terms of workload) \\
\hline
\end{tabular}

Table 7. Risk-measures evaluation methods.

\begin{tabular}{ll}
\hline Risk measures & Evaluation methods \\
\hline Schedule risk $\left(\mathrm{R}_{1}\right)$ & $\mathrm{R}_{\mathrm{c}}\left(\mathrm{PP}_{\mathrm{k}}\right)=\sum_{{ }_{i}{ }_{i}=1 P_{i}\left(C_{i}>\mathrm{duedate}\right)^{*} \mathrm{C}(\mathrm{x})}$ \\
Cost overrun $\left(\mathrm{R}_{2}\right)$ & $\mathrm{R}_{\mathrm{c}}\left(\mathrm{PP}_{\mathrm{k}}\right)=\sum_{i}^{n}{ }_{i=1} P_{i}\left(C_{i}>\mathrm{UB}\right){ }^{*} \mathrm{C}(\mathrm{x})$ \\
Performance risk $\left(\mathrm{R}_{3}\right)$ & $\mathrm{R}_{\mathrm{q}}\left(\mathrm{PP}_{\mathrm{k}}\right)=\sum_{i=1}^{n}{ }_{i=1} P_{i}\left(Q_{i}>\mathrm{Specification}\right)^{*} \mathrm{C}$ \\
\hline
\end{tabular}


Table 8. Simulation results for process plan models.

\begin{tabular}{|c|c|c|c|c|c|c|c|}
\hline & $C 1$ & $C 2$ & $C 3$ & $C 3$ & $R 1$ & $R 2$ & $R 3$ \\
\hline$P P 1$ & 18.3 & 14.2 & 0.98 & 0.90 & 0.00574 & 5.3 & 0.145 \\
\hline$P P 2$ & 19.6 & 12.14 & 0.97 & 0.93 & 0.08 & 0.95 & 0.132 \\
\hline$P P 3$ & 23.6 & 11.9 & 0.87 & 0.67 & 6.31 & 0.08 & 0.244 \\
\hline
\end{tabular}

\subsubsection{Simulation model and experimentation}

By defining a valid process model and the corresponding input variables, the model can now be translated into a simulation model. This translation involves two major activities in the context of discrete-event simulation: model coding and input variable (or parameters) feeding. The former refers to the translation of the conceptual model into a computer-simulation model, whereas the input variable feeding is the incorporation of the parameters and the preliminary data into the simulation model. Additionally, the parameters for performance measures are also fed into the simulation model. In the context of VR-PMS, the experimentation stage involves the transformation of an objective-oriented risk-aware process model into an executable computer-simulation model.

The developed model is verified and validated. Thereafter, a design of experiment, which includes activities such as determination of length of simulation, the number of runs (also called replications), and the manner of initialisation (i.e. warm period), is devised.

\subsubsection{Output data collection and analysis}

With the definition of operational simulation models (or simulated process plan alternatives) and performance and risk measures, the process plans are now ready to be simulated in the simulation environment for the purpose of performance assessment. To this end, the discrete-event simulation software Rockwell Arena V13.5 has been used.

In the current scenario, the process plans simulation is run for 10 independent replications of each process plan (PP1, PP2, and PP3). In each replication run, the process plan and scenario-related parameters as described in Tables 35 are loaded into the simulation model. The output of the simulation experiments, i.e. performance and risk measures defined already in the objectives model of VR-PMS, are collected and presented in Table 8 after statistical analysis using Output Analyser of the ARENA software.

The performance measures issued out of the simulation experiments can then be used as input to the value and risk function construction phase of the VR-PMS.

\subsection{Decision-making via multi-criteria aggregation (phase 4)}

Simulation experiments provide performance measures in quantitative terms. Performing selection among alternative process plans solely based on performance measures does not provide any insight. It is always desirable to consider multiple evaluation criteria methods when deciding among alternative solutions. For this purpose, VR-PMS employs first the MACBETH method to commensurate the PMs and then consolidates them using the Choquet integral aggregation operator.

\subsubsection{MACBETH}

MACBETH (Measuring Attractiveness by a Categorical Based Evaluation TecHnique) is a multi-criteria decision-analysis approach used to determine value functions from PMs and then aggregate them to obtain a global score (Bana e Costa, Corte, and Vansnick 2005; Clivillé, Berrah, and Mauris 2007). The strength of MACBETH lies in its structured approach towards information solicitation and its transformation into a value function employing principles of the theory

Table 9. Value and risk functions for a manufacturing scenario.

\begin{tabular}{lccccccc}
\hline & $C 1$ & $C 2$ & $C 3$ & $C 4$ & $R 1$ & $R 2$ & $R 3$ \\
\hline$P P 1$ & 0.9 & 0.6 & 0.89 & 0.33 & 0.1 & 1.0 & 0.22 \\
$P P 2$ & 0.6 & 0.5 & 0.78 & 0.17 & 0.2 & 0.29 & 0.11 \\
$P P 3$ & -0.2 & 0.2 & 0.44 & 1.0 & 1.0 & 0.14 & 0.44 \\
\hline
\end{tabular}


of measurement. The transformation of ordinal information (i.e. preference) into cardinal (i.e. strength of preference) to build a value function (interval scale) is carried out to analyse and evaluate different courses of actions.

The method requires only qualitative judgements about differences of values to help the assessor in quantifying the relative attractiveness of performance measures from a set $X=\left\{c_{1}, c_{2}, \ldots c_{n}\right\}$ over a set of alternatives $A=\left\{a_{1}, a_{2}, \ldots a_{l}\right\}$ and assigning a real number $v(c)$ to each criterion $c_{i}$ of $C$ while employing a verbal scale such as \{null, very weak, weak, moderate, strong, very strong, extreme $\}$. Because the method relies on the weighted mean to aggregate value and risk functions, which is often not the case in real-life examples where criteria may interact, VR-PMS uses MACBETH only for the construction of value and risk functions. To this end, the assessor pre-orders the alternative process plans for each criterion on the basis of their preferences (from left to right) and strengths of preferences as shown in Equation (9).

$$
\begin{aligned}
& \mathrm{C}_{1} \rightarrow \text { Good }>^{1} \mathrm{PP} 1>^{2} \mathrm{PP} 2>^{4} \text { Neutral }>^{1} \mathrm{PP} 3 \\
& \mathrm{C}_{2} \rightarrow \text { Good }>^{2} \mathrm{PP} 3>^{1} \mathrm{PP} 2>^{2} \mathrm{PP} 1>^{1} \text { Neutral } \\
& \mathrm{C}_{3} \rightarrow \text { Good }>^{1} \mathrm{PP} 1>^{1} \mathrm{PP} 2>^{2} \mathrm{PP} 3>^{3} \text { Neutral } \\
& \mathrm{C}_{4} \rightarrow \text { Good }>^{0} \mathrm{PP} 3>^{4} \mathrm{PP} 1>^{1} \mathrm{PP} 2>^{1} \text { Neutral }
\end{aligned}
$$

From this preferential information modelling, value and risk functions are determined for performance measure $c_{i}$ between alternatives $a_{k}$ and $a_{i}$ via the M-MACBETH software while employing Equation (10).

$$
v_{i}^{k}-v_{i}^{l}=h . \alpha
$$

where $h$ represents the strength of preference, which can take any value ranging from 0 to 6 ( 0 and 6 correspond to null and extreme strength of preference, respectively), and $\alpha$ is a coefficient to meet the condition $v_{i}^{k} \in[0,1]$. Therefore, the strength of preference for each measure for a set of process alternatives gives a system of equations. Solving this system of equations provides value and risk functions for each measure. The output of the MACBETH method for the defined performance and risk measures of the current example is shown in Table 9.

Once the value and risk functions for the respective performance measure and risk measure are determined, they are then aggregated independently with the help of the Choquet integral to form value and risk indicators.

\subsubsection{Choquet integral}

The Choquet integral (CI) is a multi-criteria decision method (MCDM) in its own right. It has been demonstrated how it can be used as an information aggregation mechanisms to compute performance indicators from performance measures (Berrah, Mauris, and Vernadat 2004, 2006). However, in the framework of VR-PMS, it is used only to aggregate the value and risk functions computed using the MACBETH method. For the performance measures $\mathrm{C}=\left\{\mathrm{c}_{1}, \mathrm{c}_{2} \ldots\right.$ $\left.c_{n}\right\}$ and alternative $A=\left\{a_{1}, a_{2} \ldots a_{n}\right\}$, the a of $A$ and $c$ of $C$ can be associated with a profile $x_{i}^{a}=\left(x_{c_{1}}^{a}, x_{c_{2}}^{a} \ldots x_{c_{n}}^{a}\right)$ where $\mathrm{x}_{\mathrm{i}}{ }^{\mathrm{a}}$ represents a partial score of measure $i$ in alternative $a$ on a scale of $[0,1]$.

To model the interdependencies among the performance measures, CI integral relies on Choquet capacities or fuzzy measures, which are defined as:

Let $\mathrm{P}(\mathrm{C})$ denote the power set of $C$, then a discrete fuzzy measure of $\mathrm{C}$ is a set function $u$ : $\mathrm{P}(\mathrm{C}) \longrightarrow[0,1]$ satisfying the axioms: (i) $\mathrm{u}(\emptyset)=0, \mathrm{u}(\mathrm{C})=1$ and (ii) $\mathrm{u}(\mathrm{C})>u\left(\mathrm{C}^{\prime}\right)$ if $\mathrm{C}^{\prime}$ is a subset of $\mathrm{C}$. The first axiom refers to the boundary condition, while the second one refers to monotonicity.

The discrete CI of $\mathrm{x}=\left\{\mathrm{x}_{1}, \mathrm{x}_{2} \ldots \mathrm{x}_{\mathrm{n}}\right\}$ with respect to $\mathrm{u}$ is then defined as (Grabisch and Labreuche 2009):

$$
\mathrm{C}_{\mathrm{u}}(\mathrm{x})=\sum_{i=1}^{\mathrm{n}}\left(\mathrm{x}_{i}-\mathrm{x}_{i-1} \cdot \mathrm{U}\left(\mathrm{C}^{\prime}\right)\right.
$$

Equation (11) represents the discrete CI of $x$ with respect to the fuzzy measure $\mu$. The value (.) in subscripts represents a permutation operator such that: $0 \leq x_{(1)} \leq x_{(2)} \leq \ldots \leq x_{(n)} \leq 1$.

However, the current study employs the 2 -additive CI, a special case of CI, where pairwise interactions among criteria are considered. This type of CI can be defined by Equation (12) as:

$$
\mathrm{C}_{\mathrm{u}},(\mathrm{x})=\sum_{\mathrm{i}=1}^{\mathrm{n}} \mathrm{V}_{\mathrm{i}} \mathrm{X}_{\mathrm{i}}-\frac{1}{2} \sum_{\mathrm{i}=1}^{\mathrm{n}} \mathrm{I}_{\mathrm{ij}}\left|\mathrm{x}_{\mathrm{i}}-\mathrm{x}_{\mathrm{j}}\right|
$$


Table 10. Global value and risk indicators.

\begin{tabular}{|c|c|c|c|c|c|c|c|c|c|}
\hline & $C 1$ & $C 2$ & $C 3$ & $C 4$ & Pag & $R 1$ & $R 2$ & $R 3$ & Rag \\
\hline$P P 1$ & 0.6 & 0.9 & 0.89 & 0.33 & 0.56 & 1.0 & 0.22 & 0.1 & 0.36 \\
\hline$P P 2$ & 0.5 & 0.6 & 0.78 & 017 & 0.39 & 0.29 & 0.11 & 0.2 & 0.18 \\
\hline$P P 3$ & 0.3 & -0.2 & 0.44 & 1.0 & 0.12 & 1.0 & 0.14 & 0.44 & 0.42 \\
\hline$v_{i}$ & 0.33 & 0.24 & 0.28 & 0.13 & & 0.47 & 0.18 & 0.34 & \\
\hline \multirow[t]{4}{*}{ Iij } & I12 & I13 & I14 & $\mathrm{I} 23$ & & I12 & 0.052 & 0.34 & \\
\hline & 0.049 & 0.131 & 0.049 & 0.098 & & I13 & 0.052 & & \\
\hline & $\mathrm{I} 24$ & & & $\mathrm{I} 34$ & & I23 0.10 & & & \\
\hline & 0.016 & & & 0.081 & & & & & \\
\hline
\end{tabular}

where $\mathrm{C}_{\mathrm{u}}$ models vectors of value and risk functions, $\mathrm{v}_{\mathrm{i}}$ denotes a Shapley index (with $\sum_{i=1}^{n} v_{i}=1$ ) that represents the importance of criterion i relative to all other criteria, and $\mathrm{I}_{\mathrm{ij}}$ represents the interaction between criteria $\left(\mathrm{c}_{i}, \mathrm{c}_{j}\right)$, ranging in $[-1,1]$.

For the running example, the mathematical model of Equation (12) is used to obtain the global scores, i.e. global value and risk indicators, which are presented in Table 10.

Based on the global value indicator, the alternative process plans can be ranked as:

$$
P P_{1}>P P_{2}>P P_{3}
$$

However, the ranking of alternative process plans on the basis of the global risk indicator is:

$$
P P_{2}>P P_{1}>P P_{3}
$$

Therefore, it is up to the DM to decide whether they prefer a more valuable process plan with some risk compared with a process plan with lower process value but lesser risk.

\section{Conclusion and future work}

The work reported in this paper has proposed and described a new performance measurement and management approach, called VR-PMS. It is based on the (value, risk) pair, defined in both methodological and theoretical terms, and instrumented with quantitative analysis methods and tools. The theoretical aspects of this PMM have been addressed by developing a conceptual value/risk model. It integrates objectives, activity, and risk models of any business process and defines their relationships with one another. Concerning the methodological aspects, VR-PMS proposes step-by-step guidelines to the performance evaluator or practitioner of the business process in order to tackle the performance measurement and management of the process. It has been applied to the context of a priori performance evaluation in manufacturing engineering. It can be equally applied to performance assessment of a system, project, or product.

The proposed method, as revealed in the paper, takes into account two global dimensions of performance: value and risk. The former dimension models quantitatively the 'stakeholders' satisfaction as an aggregation of performance measures derived from stakeholder's values/expectations with regard to the system, product, or process, whereas the latter determines qualitatively and quantitatively the overall risk associated with the system, product, or process, in other words, the concerns of the stakeholders in the given context.

An interesting area that remains to be explored is the extension of the framework to the concept of tolerable level of risk and tolerance on value. Having fixed a maximum level of risk and a minimum level of acceptable value, there could be situations in which the user can accept a lower value than the minimum threshold fixed if the risk is really under control (and if the cost is still profitable). Conversely, to what extent can a higher value but with a significantly higher risk be accepted? In addition, determining these minimum and maximum levels of risk and value as well as tolerances on these levels would also be interesting questions to investigate. Finally, the proposed method will be extended to include the cost and benefits dimensions in order to make it a complete global performance management framework based on cost, benefits, value, and risk (CBVR).

\section{References}

Acar, Y., S. Kadipasaoglu, and P. Schipperijn. 2010. "A decision support framework for global supply chain modeling: an assessment of the impact of demand, supply and lead-time uncertainties on performance." International Journal of Production Research 48 (11): 3245-3268.

Anselmetti, B. 2008. Manuel de tolérancement: Volume 2, Bases de la cotation fonctionnelle. Hermès Science Publications, Paris (in French). 
Bacidore, J. M., J. A. Boquist, T.T. Milbourn, and A.V. Thakor. 1997. "The Search for the Best Financial Performance Measure." Financial Analysts Journal 53: 11-20.

Bana e Costa, C., J. M. Corte, and J.C. Vansnick. 2005. On the Mathematical Foundation of MACBETH. Multiple Criteria Decision Analysis: State of the Art Surveys 409-437.

Bana e Costa, C.A., J. M., de Corte, and J.C. Vansnick. 2003. Macbeth. Working Paper 03.56, London School of Economics, London, UK.

Berrah, L., G. Mauris, and F. Vernadat. 2004. "Information aggregation in industrial performance measurement: rationales, issues and definitions." International Journal of Production Research 42 (20): 4271-4293.

Berrah, L., G. Mauris, and F. Vernadat. 2006. "Industrial performance measurement: An approach based on the aggregation of unipolar or bipolar expressions, Special issue on "The networked enterprise: a challenge for sustainable development"." International Journal of Production Research 44 (18-19): 4145-4158.

Berrah, L., and F. Vernadat. 2011. Towards a system-based model for overall performance evaluation in a supply chain context. The Open Industrial and Manufacturing Engineering Journal, 5.

Bharara, A., and C. -Y. Lee. 1996. "Implementation of an activity-based costing system in a small manufacturing company." International Journal of Production Research 34: 1109-1130.

Bititci, U., P. Garengo, V. Dörfler, and S. Nudurupati. 2011. "Performance Measurement: Challenges for Tomorrow." International Journal of Management Reviews 14 (3): 305-327.

Bitton, M. 1990. ECOGRAI: Méthode de conception et d'implantation de systèmes de mesure de performances pour organisations industrielles. Ph.D dissertation, University of Bordeaux 1, Bordeaux, France.

Bosilj-Vuksic, V., V. Ceric, and V. Hlupic. 2007. "Criteria for the evaluation of business process simulation tools." Interdisciplinary Journal of Information, Knowledge, and Management 2: 73-88.

Bourne, M., M. Franco, and J. Wilkes. 2003. “Corporate performance management.” Measuring Business Excellence 7: 15-21.

Brimson, J. A. 1997. Activity Accounting: An Activity-Based Costing Approach. 1st edition New-York, NY: Wiley \& Sons.

Chan, F. T. S., and H. Qi. 2003. "Feasibility of performance measurement system for supply chain: a process-based approach and measures." Integrated Manufacturing Systems 14: 179-190.

Clivillé, V., B. Berrah, and G. Mauris. 2007. "Quantitative expression and aggregation of performance measurements based on the MACBETH multi-criteria method.” International Journal of Production Economics 105: 171-189.

Cokins, G. 2012. Kaplan and Norton's future vision of the Balanced Scorecard: Closing the Intelligence Gap. URL http://blogs.sas. com/content/cokins/2012/04/17/kaplan-and-nortons-future-vision-of-the-balanced-scorecard.

Deming, W. E. 1982. Quality, Productivity and Competitive Position. Massachusetts Institute Technology, Cambridge, MA.

Ducq, Y., and B. Vallespir. 2005. "Definition and aggregation of a performance measurement system in three aeronautical workshops using the ECOGRAI method.” Production Planning \& Control 16: 163-177.

Folan, P., and J. Browne. 2005. "A review of performance measurement: Towards performance management." Computers in Industry 56: $663-680$.

Globerson, S. 1985. "Issues in developing a performance criteria system for an organization." International Journal of Production Research 23: 639-646.

Goldratt, E. M. 1990. What is this thing called theory of constraints and how should it be implemented?. Great Barrington, MA: North River Press.

Goldratt, E. M. 1999. Theory of Constraints. 1st edition Great Barrington, MA: North River Press.

Grabisch, M., and C. Labreuche. 2009. "A decade of application of the Choquet and Sugeno integrals in multi-criteria decision aid." Annals of Operations Research 175: 247-286.

Gunasekaran, A., C. Patel, and R. E. McGaughey. 2004. "A framework for supply chain performance measurement." International Journal of Production Economics 87: 333-347.

Gunasekaran, A., and B. Kobu. 2007. "Performance measures and metrics in logistics and supply chain management: a review of recent literature (1995-2004) for research and applications." International Journal of Production Research 45 (12): $2819-2840$.

Hayes, R. H., and W. J. Abernathy. 1980. Managing our way to economic decline. Harvard Business Review, 58.

Johnson, H. T., and R. S. Kaplan. 1987. Relevance lost: The rise and fall of management accounting. Harvard Business School Press.

Kaplan, R. S. 1984. "The Evolution of Management Accounting." The Accounting Review 59: 390-418.

Kaplan, R. S., and R. Cooper. 1998. Cost \& effect: using integrated cost systems to drive profitability and performance. Harvard Business Press.

Kaplan, S., and B. J. Garrick. 1981. "On The Quantitative Definition of Risk.” Risk Analysis 1: 11-27.

Kaplan, R. S., and D. P. Norton. 1992. "The Balanced Scorecard: Measures That Drive Performance." Harvard Business Review 70 (1): 71-79.

Kaplan, R. S., and D. P. Norton. 1996. "Using the balanced scorecard as a strategic management system." Harvard Business Review 74: $75-85$.

Kaplan, R. S., and D. P. Norton. 2004. Strategy maps: converting intangible assets into tangible outcomes. Harvard Business Press.

Keeney, R. L. 1996. Value-Focused Thinking: A Path to Creative Decision-making. Harvard University Press.New ed.

Kueng, P. 2000. "Process performance measurement system: a tool to support process-based organizations." Total Quality Management 11: 67-85. 
Larson, N., and A. Kusiak. 1996. "Managing design processes: A risk assessment approach." IEEE Transactions on Systems, Man, and Cybernetics- Part A: Systems and Humans 26: 749-759.

Lynch, R. L., and K F. Cross. 1992. "The SMART way to define and sustain success." National Productivity Review 8: $23-33$.

Meyer, M. W. 2003. Rethinking Performance Measurement: Beyond the Balanced Scorecard. Cambridge, MA: Cambridge University Press.

Moeller, R. 2007. COSO Enterprise Risk Management: Understanding the New Integrated ERM Framework. 1st ed. New-York, NY: Wiley \& Sons.

Narasimhan, R., and S. Talluri. 2009. "Perspectives on risk management in supply chains." Journal of Operations Management 27: $114-118$.

Neely, A., M. Gregory, and K. Platts. 2005. "Performance measurement system design: a literature review and research agenda." International Journal of Operations \& Production Management 25: 1228-1263.

Neely, A., C Adam, and M. Kennerley. 2002. The Performance Prism: The ScoreCard for Measuring and Managing Business Success. London: Prentice Hall.

Nudurupati, S. S., U. S. Bititci, V. Kumar, and F. T. S. Chan. 2011. "State of the art literature review on performance measurement." Computers \& Industrial Engineering 60: 279-290.

Skinner, W. 1973. The decline, fall, and renewal of manufacturing plants. Graduate School of Business Administration, Harvard University. Division of Research.

Slack, N. 1983. "Flexibility as a manufacturing objective." International Journal of Operations \& Production Management 3: 4-13.

Salah, E., and E. 2005. "On the fallacy of averages in project risk management." European Journal of Operational Research 165: 307-313.

Shah, L. 2012. Value/Risk -based Performance Evaluation of Industrial Systems. Ph.D. Thesis, Ecole Nationale Supérieure des Arts et Métiers, Metz, France.

Shah, L., A., Etienne, A., Siadat, and F. Vernadat. 2012. (Value, Risk)-Based Performance Evaluation of Manufacturing Processes, Proc. 14th IFAC Symposium on Information Control Problems in Manufacturing (INCOM 2012), Bucharest, Romania, 23-25 May 2012, pp. 1586-1591.

Sormaz, D. N., and B. Khoshnevis. 2003. "Generation of alternative process plans in integrated manufacturing systems." Journal of Intelligent Manufacturing 14: 509-526.

Stalk, G. 1988. “Time-The Next Source of Competitive Advantage.” Harvard Business Review 66 (4): 41-51.

Stern, J. M., G. B. Stewart, and D. H. Chew. 1995. “The EVA financial management system.” Journal of Applied Corporate Finance 8: 32-46.

Van Lamsweerde, A., and E. Letier. 2000. "Handling obstacles in goal-oriented requirements engineering." IEEE Transactions on Software Engineering 26: 978-1005. 